\title{
Research of the Improved Eco-Efficiency Evaluation Model of Iron and Steel Industry Based on PCA
}

\author{
Xinghuo Wan, Honglian Wang, Lihui Zhou* and Huijiao Gao \\ College of Science, Hebei United University, Tangshan, Hebei, 063009, China
}

\begin{abstract}
In this paper, we will establish an Eco-efficiency evaluation index system which is based on the characteristics of the steel industry. Using the principal component analysis to eliminate the impact of the evaluation, reduce the workload of the selection of indicators, and establish the DEA model of the iron and steel industry Eco-efficiency. Finally, we test and verify the effectiveness of this method through simulating the date of the 10 iron and steel companies of Tangshan. by using the MATLAB software.
\end{abstract}

Keywords: Data envelope analysis (DEA), eco-efficiency, evaluation model, principal component analysis.

\section{INTRODUCTION}

It is the main direction of the development of China's iron and steel industry that we want to achieve the ecological transformation of the iron and steel industry, build a resource-saving and environment-friendly enterprise. In order to promote the development of the circular economy, assess the ecological construction and transformation process, we need to use the scientific methods to evaluate and provide a scientific basis for government and enterprises decision. Eco-efficiency is refer that through the offer to meet human needs and improve the quality of life of competitive pricing of goods and services, and reduce the entire life cycle of ecological impacts and resource intensity to a minimum consistent with the carrying capacity of the Earth level [1]. In terms of the industry, it requires industrial enterprises to use minimal resources and energy to create most products in the production process, and have minimal impact on the environment, achieve a win-win economic and environmental benefits, and achieve the sustainable development of the industry ultimately. Eco-efficiency provides an important means and tools for the industry about sustainable development agenda [2]. In this paper, we depend on the circular economy of the iron and steel industry development and the ecological transformation, letting Eco-efficiency as the main line, and we investigate the Meaning of the iron and steel industry Ecoefficiency. Through the study of the principles of the principal component analysis, we establish the iron and steel industry improved Eco-efficiency evaluation model which based on the iron and steel industry Eco-efficiency evaluation model. Finally, we evaluate the model.

\section{THE OBJECTIVES AND PRINCIPAL OF TANG- SHAN IRON AND STEEL INDUSTRY ECO- EFFICIENCY EVALUATION}

Evaluating Tangshan Iron and Steel Industrial Ecoefficiency is the premise about circular economy research from theoretical discussion stage to the actual operation phase. Through evaluation we should achieve the following specific objectives [3].

Firstly, we want to evaluate the status of the development of the circular economy of Tangshan iron and steel industry. We hope to reflect the health of the construction of circular economy of the steel industry through evaluating Ecoefficiency. We can judge and measure the level of development about ecological restructuring of the Tangshan iron and steel industry.

Secondly, we can monitor the trends of Tangshan iron and steel industry Eco-efficiency. We can reflect the trends of the circular economy development of Tangshan iron and steel industry by detecting the long-term dynamics of the steel industry in Eco-efficiency related data.

Thirdly, we can provide a basis for optimizing management decisions, you can understand the status of the development of Tangshan iron and steel industry, provide a scientific basis for the optimization of management decisions by evaluating.

Eco-efficiency evaluation should be able to let the public understand the cycle of economic development and provide the necessary information and evidence for the government. For this purpose, the selection of indicators should be selected follow certain principles. Including: (1) Eco-efficiency evaluation must be accurate, comprehensive coverage the goals, connotation, characteristics and principles of the development of recycling economy. (2) Eco-efficiency evaluation index system should be highlight the focus resources and environmental indicators [4], complemented by economic indicators. (3) The level of circular economic indicators muse have broad, more comprehensive and accurate reflection of the level of Eco-efficiency of steel companies. (4) We should focus on the time, place and scope of comparability when we choose the indicators. Therefore we should be clear the connotation of each index, statistical and scope, ensure the comparability. 


\section{CHOOSE THE IRON AND STEEL INDUSTRY ECO-EFFICENCY EVALUATION INDEX}

We base on the fundamental principles and objectives when we choose the Eco-efficiency evaluation of Tangshan iron and steel industry. According to the connotation of the circular economy, we hope to cover the economic, resource and environmental dimensions. We choose the amount of water, energy consumption, employment, enterprise size, capitalization, waste-water emissions, $\mathrm{SO}_{2}$ emissions, emissions, waste emissions, industrial added value, gross profit, they as a DEA method to input and output indicators [3]. There have eleven primary indicators. Among them, water, energy consumption, employment, enterprise size is a resource consumption, waste-water emissions, $\mathrm{S}_{2}$ emissions, emissions, waste emissions is the environmental impact, industrial added value, gross profit is economic value.

It can be seen in summary, since we considered more factors and wide aspect, we get too much iron and steel industry Eco-efficiency evaluation. The relevant indicators also have a certain correlation. Such as, industrial added value and total profits have overlapping terms. Based on this situation, we make some improvements on the Eco-efficiency evaluation model for the iron and steel industry.

\section{CHOOSE THE IRON AND STEEL INDUSTRY ECO-EFFICENCY EVALUATION INDEX BASED ON PCA OF ECO-EFFICENCY EVALUATION MODEL}

Principal component analysis also known as principal component analysis, aims to use the idea of reducing the number of dimensions, lets the multiple indexes into a few comprehensive indexes [5]. In the study of the empirical questions, we must consider many factors to analyze the problem comprehensively. These factors are known as targets generally, they also known as variable in multivariate statistical analysis. Because each variable reflects some information of the research questions and indexes have some correlation with each other, statistics information which obtained reflect some extent overlap. We use the statistical methods when we study multi-variable questions, and too many variables will increase the amount of computation and the complexity of the analysis of the problem. People want to involve fewer variables and obtain a larger amount of information at the process of performing quantitative analysis the process of quantitative analysis. Principal component analysis is the ideal tool which meets this requirement and solves these problems.

Number of the steel industries which should be evaluated are $n$, number of Eco-efficiency evaluation are $m$. The matrix of sample data as follows:

$$
X=\left|\begin{array}{cccc}
x_{11} & x_{21} & \ldots & x_{n 1} \\
x_{12} & x_{22} & \ldots & x_{2 n} \\
\ldots & \ldots & \ldots & \ldots \\
x_{1 m} & x_{2 m} & \ldots & x_{n m}
\end{array}\right|
$$

We can see the result through normalizing the above matrix:
$Z_{j}=\frac{x_{i j}-\bar{x}_{j}}{s_{j}}$

In the above formula: $\bar{x}_{j}=\frac{1}{n} \sum_{i=1}^{n} x_{i j}, s_{j}^{2}=\frac{1}{n-1} \sum_{i=1}^{n}\left(x_{i j}-\bar{x}_{j}\right)$

$$
i=1,2, \ldots, n, j=1,2, \ldots, m
$$

We can obtain the correlation matrix of Eco-efficiency $R=\left(r_{i j}\right)_{m \times m}$ based on the formula $r_{j k}=\frac{1}{n} \sum_{i=1}^{n} Z_{i j} Z_{j k}$, so we can calculate the characteristic roots of the correlation matrix: $\lambda_{1} \geq \lambda_{2} \geq \ldots \geq \lambda_{m} \geq 0$. Corresponding eigenvectors are $L_{j}=\left(l_{j 1}, l_{j 2}, \ldots, l_{j m}\right)^{T}, j=1,2, \ldots, m$. So we can convert the characteristic scalars normalized into principal components, as follows:

$$
\begin{aligned}
F_{j} & =Z L_{j}=l_{j 1} Z_{1}+l_{j 2} Z_{2}+\ldots+l_{j m} Z_{m} \\
j & =1,2, \ldots, m
\end{aligned}
$$

If the main component of the cumulative contribution rate is: $\sum_{j=1}^{k}\left(\lambda_{j} / \sum_{j=1}^{m} \lambda_{j}\right) \geq 85 \%(k<m)$, we select the principal components as the main component variables, namely, the new comprehensive index. Then we put the comprehensive indicators selected by the principal component analysis and the data of Eco-efficiency into the first model. Finally, we can use the DEA software and obtain the result.

Banker, Charnes and Cooper modified the earlier DEA model based on the assumption of variable returns to scale and established the BCC model [6].

The linear programming model is:

$$
\begin{aligned}
& \min \theta \\
& \text { s.t. }\left\{\begin{array}{l}
\sum_{j=1}^{n} \lambda_{j} x_{j} \leq \theta x_{0} \\
\sum_{j=1}^{n} \lambda_{j} y_{j} \geq y_{0} \\
\sum_{j=1}^{n} \lambda_{j}=1 \\
\lambda_{j} \geq 0, j=1,2, \ldots, n
\end{array}\right.
\end{aligned}
$$

The model adds a constraint, such as $\sum_{j=1}^{n} \lambda_{j}=1$, therefore, we calculate a pure technical effectiveness. When the technical efficiency of the decision-making unit is 1 , and according to the model and software analysis, we can obtain the result of Eco-efficiency of Tangshan iron and steel industry, then we can analyze and evaluate the status.

\section{ECO-EFFICENCY OF TANGSHAN IRON AND STEEL ENTERPRISES' SIMULATION ANALYSIS}

According to the various factors of Tangshan iron and steel production, we will put ten enterprises of Tangshan into 
Table 1. The variance contribution rate of input variables.

\begin{tabular}{|c|c|c|}
\hline Ingredient & $\begin{array}{c}\text { Variance Contribution } \\
\text { Rate\% }\end{array}$ & $\begin{array}{c}\text { The Cumulative Variance } \\
\text { Contribution Rate\% }\end{array}$ \\
\hline \hline$x_{1}$ & 39.739 & 39.739 \\
\hline$x_{2}$ & 31.026 & 70.766 \\
\hline$x_{3}$ & 15.590 & 86.356 \\
\hline
\end{tabular}

Table 2. The variance contribution rate of output variables.

\begin{tabular}{|c|c|c|}
\hline Ingredient & $\begin{array}{c}\text { Variance Contribution } \\
\text { Rate\% }\end{array}$ & $\begin{array}{c}\text { The Cumulative Variance } \\
\text { Contribution Rate\% }\end{array}$ \\
\hline \hline$x_{5}$ & 46.238 & 46.238 \\
\hline$x_{6}$ & 21.23 & 67.468 \\
\hline$x_{7}$ & 15.34 & 82.808 \\
\hline$x_{8}$ & 13.264 & 96.072 \\
\hline
\end{tabular}

this model, such as, Tangshan Iron \& Steel Co., Tangshan Iron and Steel Group Kim Heng Enterprise Development Corporation welfare Plant and so on. Because the date is not easy to obtain, we choose the form to simulate the date and validate the principal component analysis method.

Finally, we select the amount of salary, energy consumption, total wages, the total amount of capital, the amount of waste water, the amount of exhaust gas, waste displacement, the total amount of taxes and the industrial added value as the indicator variables.

Firstly, we use the principal component analysis to analyze the Eco-efficiency of the iron and steel industry. We use the SPSS software analyze the input variables and output variables based on principal component analysis, and get the cumulative variance contribution rate, as shown in Table $\mathbf{1}$ and 2.

We can know the information that input and output indicators contribution rate have reached $86.356 \%, 96.072 \%$ from the cumulative variance contribution rate, so we can select the seven principal components into the model.

Secondly, we use the DEA model to analyze and evaluate the date. The results as shown in Table 3:

In this model, we don't use the principal component analysis. We let the date into the DEA model and obtain the result as shown in Table 4.

Finally, comparing the average of Table $\mathbf{3}$ and $\mathbf{4}$, we can see that the overall efficiency, the scale efficiency and the technical efficiency, which used principal component analysis, is similar with the result which doesn't use the principal component analysis.

\section{CONFLICT OF INTEREST}

There are many Eco-efficiency indicators in the iron and steel industry, and their mutual relations are very complex.
Table 3. Tangshan Eco-efficiency value of the ten iron and steel companies.

\begin{tabular}{|c|c|c|c|}
\hline Enterprise & \multicolumn{3}{|c|}{$\mathbf{2 0 1 2}$} \\
\hline & CCR & SE & BBC \\
\hline \hline 2 & 0.910 & 0.914 & 0.995 \\
\hline 3 & 0.806 & 0.856 & 0.941 \\
\hline 4 & 0.980 & 0.981 & 1.000 \\
\hline 5 & 0.717 & 0.717 & 1.000 \\
\hline 6 & 0.631 & 0.632 & 0.999 \\
\hline 7 & 1.000 & 1.000 & 1.000 \\
\hline 8 & 0.928 & 1.000 & 0.928 \\
\hline 9 & 1.000 & 1.000 & 1.000 \\
\hline 10 & 0.752 & 0.772 & 0.974 \\
\hline Average & 0.751 & 1.000 & 0.751 \\
\hline
\end{tabular}

Table 4. Tangshan Eco-efficiency value of the ten iron and steel companies.

\begin{tabular}{|c|c|c|c|}
\hline \multicolumn{2}{|c|}{ Enterprise } & \multicolumn{2}{c|}{ 2012 } \\
\hline \hline 1 & CCR & SE & BBC \\
\hline \hline 2 & 0.910 & 0.914 & 0.995 \\
\hline 3 & 0.806 & 0.856 & 0.941 \\
\hline 4 & 0.980 & 0.981 & 1.000 \\
\hline 5 & 0.717 & 0.717 & 1.000 \\
\hline 6 & 0.631 & 0.632 & 0.999 \\
\hline 7 & 1.000 & 1.000 & 1.000 \\
\hline 8 & 0.928 & 1.000 & 0.928 \\
\hline 9 & 1.000 & 1.000 & 1.000 \\
\hline 10 & 0.752 & 0.772 & 0.974 \\
\hline Average & 0.751 & 1.000 & 0.751 \\
\hline
\end{tabular}

Then we use the principal component analysis to overcame the one-sidedness and subjectivity of the traditional models. And this model can eliminate the correlation between the indicators and reduce the amount of computation. It provides an easy, express and effective way to analyze and evaluate date by the DEA model.

\section{ACKNOWLEDGEMENTS}

This work is supported by the t mayor of Tangshan City Special Projects (No. 13110203A), Hebei soft science project (No. 13453815), the National Natural Science Fund (No. 
11401160) and the Students' Innovation Project (No. X2014107). Thanks.

\section{REFERENCES}

[1] Jacqueline Cramer. Early warning:integrating Eco-efficiency aspects into the products development process. Journal of Environment Quality Management: 1-10. 2000

[2] Dajian Zhu, Yuan Zhu. Eco-efficiency and recycling economy. Journal of Fudan University (2): 60-66, 2005.

[3] Chunli Du. On Ecology Efficiency Evaluation for Iron\&Steel Industry of China Based On Circular Economy[D]. Doctoral Dissertation of Geology University of China: 65-80 .2009.
[4] Dajian Zhu, Yuan Zhu. Recycling economy: deepening the three aspects research. Journal of social science(4):52-53. 2006.

[5] Ning Liu, Xiaoqing Wu, Zhifeng Wang, Yan Wang. Eco-efficiency Assessment of Industrial Symbiosis Based on Principal Component Analysis. Journal of Resources and Environment of Wall Basin(6): 831-838, 2008.

[6] Fare, R., Grosskopf, S., Lovell, C. A. K., Pasurka, C., Multilateral productivity comparisons when some outputs are undesirable: a nonparametric approach. Journal of the Review of Economics and Statistics.71: 90-98.1989.

[7] Bing Li. Energy Saving and Recycling Economy Construction System of The Iron and Steel Industry. Journal of Resources Comprehensive Utilization China(6): 12-14 .2008.

Received: September 22, 2014

Revised: November 30, 2014

Accepted: December 02, 2014

(C) Wan et al.; Licensee Bentham Open.

This is an open access article licensed under the terms of the Creative Commons Attribution Non-Commercial License (http://creativecommons.org/licenses/by-nc/3.0/) which permits unrestricted, non-commercial use, distribution and reproduction in any medium, provided the work is properly cited. 